\title{
Introduction to Basal Ganglia X - proceedings of the 10th Triennial Meeting of the International Basal Ganglia Society
}

\author{
James M. Tepper* \\ Rutgers, The State University of New Jersey, Newark, NJ, USA \\ *Correspondence: jtepper@andromeda.rutgers.edu
}

\section{INTRODUCTION}

The International Basal Ganglia Society (IBAGS) had its origins in 1983 at a Satellite Meeting of the International Union of Physiological Sciences held at Lorne, Australia. At that meeting Professor John McKenzie organized a symposium devoted to the structure and function of the basal ganglia that attracted some 50 attendees from 12 countries. Thirty years later, IBAGS has grown into international organization with over 400 members from over 30 countries spanning the entire world. More information about the history of IBAGS and its previous triennial meetings can be found at www.ibags.info.

The present volume consists of contributions from attendees of the Tenth Triennial Meeting of IBAGS, held June 20th-24th, 2010, at the Ocean Place Resort in Long Branch, NJ, USA, on the Jersey shore. The meeting attracted 278 scientific attendees representing over 30 different countries. The program included 50 invited speakers and over 180 poster presentations. The scientific sessions comprised a broad range of themes including "New Insights Into Basal Ganglia Diseases From Genetic Models," "Novel and Understudied Basal Ganglia Circuits and Pathways," "What Do the Basal Ganglia Really Do," "Cognitive Functions of The Basal Ganglia," "NonMotor Sequela of Basal Ganglia Diseases," "Dysfunction of the Basal Ganglia in Dystonia And Dyskinesia," "Atypical Neuromodulators in the Basal Ganglia - Beyond Acetylcholine and Dopamine," and "Basal Ganglia Function: Novel Insights From Computational Modeling." Other highlights of the meeting included the Keynote Lecture on optogenetics by Karl Diesseroth, the Special Lecture by Charlie Wilson who was inducted as the 6th IBAGS Lifetime Member, and the lobster cook-out and bonfire on the beach. And of course, the welcome attendance and energetic participation of John McKenzie, some 30 years after he organized the meeting that gave birth to IBAGS.

After all previous IBAGS meetings, contributions were solicited from attendees that were published as a single, hardcover volume. This volume, and the contributions in it, were not-peer reviewed nor indexed by PubMed or other commonly used databases. Thus the articles written were principally available only to IBAGS members or others who had purchased the (usually expensive) volume. For IBAGS X, we elected to take advantage of modern technology and publish the proceedings electronically, as a Special Topics Issue of Frontiers in Systems Neuroscience. All submissions were subject to the normal Frontiers journals' peer review system, and virtually all of the accepted submissions were published on-line within 2 weeks of final acceptance. For the first time, the IBAGS proceedings articles are all indexed and searchable in PubMed and other scientific indexing services, and freely available to anyone with an internet connection.
Now, that the last of the submissions have been reviewed and accepted for publication, the 46 articles resulting from IBAGS X have been sorted into 7 topics (Basal Ganglia Electrophysiology, Basal Ganglia Pharmacology, Basal Ganglia Anatomy, Genetic Models of Basal Ganglia Disorders, Basal Ganglia Function in Health and Disease, Learning in the Basal Ganglia and Computational Approaches to the study of the Basal Ganglia) and compiled into this e-book. We hope you find the collection interesting and valuable.

We all look forward to IBAGS XI, which is scheduled to take place in Eilat, Israel, in March 2013, under the direction of Hagai Bergman and Izhar Bar-Gad.

\section{IBAGS X OFFICERS AND COMMITTEES \\ OFFICERS}

President

- James M. Tepper, USA

Past President

- Henk Groenewegen, Netherlands

President-elect

- Hagai Bergman, Israel

Secretary

- Elizabeth. D. Abercrombie, USA

Secretary-elect

- Izhar Bar-Gad, Israel

Treasurer

- Yoland Smith, USA

\section{LOCAL ORGANIZING COMMITTEE}

- James M. Tepper, USA

- Elizabeth D. Abercrombie, USA

- Mark Bevan, USA/UK

- Savio Chan, USA

- Carlos Cepeda, USA

- Kristin Keefe, USA

- Carlos Paladini, USA

\section{PROGRAM COMMITTEE}

- Mike Levine, Chair, USA

- Thomas Boraud, France

- Micaela Morelli, Italy

- Lynn Raymond, Canada

- Margaret Rice, USA

- Jochen Roeper, Germany

- Ed Stern, Israel

- Kuei-Yan Tseng, USA 
- Tom Wichmann, USA

- Jeff Wickens, New Zealand

TRAVEL FELLOWSHIP COMMITTEE

- Tony West, Chair, USA

- Stephanie Cragg, UK

- Atsushi Nambu, Japan

\section{IBAGS X COUNCIL}

- Erwan Bezard, France

- Angela Cenci-Nilsson, Sweden

- David Finkelstein, Australia

- Pete Magill, UK

- Micaela Morelli, Italy

- Atsushi Nambu, Japan

- José Obeso, Spain
- Jochen Roeper, Germany

- Abbas Sadikot, Canada

- Henk Berendse, Netherlands

\section{ACKNOWLEDGMENTS}

The National Institute of Neurological Disorders and Stroke (NINDS), Pfizer, The Kenneth Aidekman Family Foundation, and Eli Lily and Company are gratefully acknowledged for their financial support of IBAGS X.

Received: 05 April 2012; accepted: 05 April 2012; published online: 01 May 2012. Citation: Tepper JM (2012) Introduction to Basal Ganglia X - proceedings of the 10th Triennial Meeting of the International Basal Ganglia Society. Front. Syst. Neurosci. 6:29. doi: $10.3389 /$ fnsys.2012.00029

Copyright $\odot 2012$ Tepper. This is an open-access article distributed under the terms of the Creative Commons Attribution Non Commercial License, which permits non-commercial use, distribution, and reproduction in other forums, provided the original authors and source are credited. 